\title{
How Are the Landscape Problems in Post-Communist Countries Solved?-Examples from Central European Region (The Czech and Slovak Republic)
}

\author{
Zuzana Dvořáková Líšková ${ }^{*}$, Petra Pártlováa ${ }^{2}$, Dagmar Škodová Parmová ${ }^{3}$, Eva Semančíková4 \\ ${ }^{1}$ Department of Regional Development and Law, Faculty of Economics, University of South Bohemia, České Budějovice, Czech \\ Republic \\ ${ }^{2}$ Department of Management, Faculty of Corp. Strategy Institute of Technology\& Business, České Budějovice, Czech Republic \\ ${ }^{3}$ Department of Applied Economics and Economy, Faculty of Economics, University of South Bohemia, České Budějovice, Czech \\ Republic \\ ${ }^{4}$ Department of Ecosystem Biology, Faculty of Science, University of South Bohemia, České Budějovice, Czech Republic \\ Email: *zuli@ef.jcu.cz
}

How to cite this paper: Líšková, Z. D. Pártlová, P., Parmová, D. S., \& Semančíková, E. (2021). How Are the Landscape Problems in Post-Communist Countries Solved?-Examples from Central European Region (The Czech and Slovak Republic). Current Urban Studies, 9, 464-480.

https://doi.org/10.4236/cus.2021.93029

Received: July 15, 2021

Accepted: August 30, 2021

Published: September 2, 2021

Copyright $\odot 2021$ by author(s) and Scientific Research Publishing Inc. This work is licensed under the Creative Commons Attribution International License (CC BY 4.0).

http://creativecommons.org/licenses/by/4.0/

\begin{abstract}
The paper deals with the "top-down" approach because its existence should define limits for the "bottom-up" approach. The paper is focused on the existence and operation of the system of hierarchical planning of landscape in two post-communist countries-the Czech and Slovak Republic. A significant output of our study is how the individual documents deal with landscape and methodology, based on which it is possible to compare given documents and their quality.
\end{abstract}

\section{Keywords}

Situational Analysis, Value Potential, Methods of Management, Landscape Problems

\section{Introduction}

The gradual increase in the extent and intensity of human activities in the landscape has been accompanied by some negative impacts, especially in biological components, i.e., the originally natural environment (Antrop \& Van Eetvelde, 2000; Hersperger \& Bürgi, 2009; Kadlecová et al., 2012; Ndubisi, 2002). The adverse effects have resulted in a gradual overgrowth of the first local environmental problems to a regional nature and have led to global environmental problems 
recently (Naveh, 2001; Palang et al., 2000; Palang et al., 2005; Walz, 2011). The representatives of more and more states have gradually realized such a negative trend of intensifying human activities on different components of the landscape. Many human activities and their impacts on human societies' environments have outgrown their solution's boundaries and possibilities. This event was a prerequisite for the European Landscape Convention (Council of Europe Portal, 2021).

Environmental problems are seen in the landscape the most often, can be divided into problems from the perspective of quality of particular ecosystems (degradation of landscape units, degradation of biodiversity, degradation of landscape functions, degradation of landscape diversity, the threat for landscape services from particular ecosystems); and from the spatial point of view of (fragmentation of the landscape, Appropriation of free land, change of landscape, leaving the landscape, non-improved landscape.

Nature and landscape policies (Kessler, 2003; Pinto-Correia et al., 2018) were insufficiently developed in terms of the intensity of growing issues. Specific measures have been gradually adopted, focusing solely on dealing with local and regional issues (Boháčková \& Hrabánková, 2006; Fraser et al., 2006; Primdahl, 2014). Landscape issues can be seen on local, regional, and global scales and need to be solved on these levels. From this point of view, we need to create political plans, management plans, and implementing projects, leading to the prevention and remedy of landscape problems and permanently sustainable landscape use.

The use of instruments in different states is relatively differentiated. The choice is always derived from dealing with the specific issues of the state and the goal that is preferred to be achieved (Stürck \& Verburg, 2017; Millennium Ecosystem Assessment, 2005). Instruments of landscape and nature protection can be divided into instruments of direct effect of administrative-legal instruments, conceptual tools, and administrative contracts and other voluntarily assumed commitments and instruments of indirect action, which include mainly economic instruments (Oliveira \& Hersperger, 2018). Economic instruments are either negative (fees for entry to national parks) or positive, promoting activities with positive environmental effects and landscape conservation and care (such as grants, subsidies, tax, and loans etc.). Landscape planning is related to the preparation, coordination, and management of human activity in a particular landscape area. In general, the landscape-ecological and socio-economic knowledge of an area should be the base; in other words, harmonizing socio-economic activities with the landscape potential of sustainability should be the aim (Syrbe \& Walz, 2012).

Hierarchical planning is a suitable tool of effective landscape planning (Boucnikova et al., 2005; Ndubisi, 2014). Hierarchical planning in the landscape is determined by setting goals, and processes, resources, tasks. There are strategic, operative, and tactical goals. After setting the goals, strategic, tactical, and operational plans and nature and landscape conservation programs are defined. Strategic planning is set for an extended period and affects large territorial units 
(Allmendinger \& Haughton, 2010; Bunnell \& Boyland, 2003). Tactical planning is medium-term, and goals are set for medium-sized regions, using different tools, means, and methods (Kessler, 2000). Operational planning is short-term and at the lowest spatial level (Allmendinger \& Haughton, 2013). Hierarchical planning is an example of a top-down approach and is therefore initiated by legislative needs (Fraser et al., 2006).

Environmental protection was an important area of the transformation process that started in 1989. The Czech Republic and Slovakia were part of the CSFR, and the whole environmental protection system went through a change. There was a demand for creating a legislative basis and its successive approximation in connection with the EU's preparation for accession. Institutional apparatus was needed to be eradicated, new territorial governance set up, and a whole set of programming documents created, including the rewording of objectives and corresponding principles and instruments (Bičík et al., 2015; Lipský, 1995).

The newly formulated environmental policy was fully based on the need to align the Czech Republic and Slovakia's specific priorities with the requirements related to the upcoming accession to the European Union. State Nature and Landscape Protection Programs were adopted (Jehlička \& Smith, 2011; Pražan et al., 2005; Růžička \& Miklós, 1990).

Currently, there is a significantly different qualitative development in both countries. Many program documents have emerged in the Czech Republic and Slovakia based on international conventions and agreements (Table 1). These documents affect landscape work and propose tools to tackle landscape issues, either directly or indirectly. Long-term, strategic, and medium-term tactical documents were developed at the national level to protect the environment in all its components to ensure sustainable development and harmonization of the territory.

\section{Material and Methods}

For this paper's purpose, an outline of all currently valid strategic and tactical documents was carried out at the national level in the Czech Republic and in Slovakia (see Table 1), which can affect landscape or its particular elements due to their content. Consequently, a scheme has been made, displaying the order of documents as they follow, from which European standards and agreements they come, and which tactical documents they develop.

We chose those used mainly as an endowment for the solution of landscape problems from the tactical documents. The exception is tactical documents such as Spatial Development Policy and Conception of Spatial Development of Slovakia, which is the only documents implemented in the Act No. 183/2006 Coll., on landscape planning and building code and Act of NR SR No. 237/2000 Coll. on landscape planning and building code.

Current problems in the landscape were defined to perform the analysis of documents. A complete characteristic of current landscape problems is shown in 
Table 1. Outline of studied strategic and tactical documents a) Czech Republic; b) Slovak Republic, own work.

\begin{tabular}{|c|c|c|}
\hline Issued by & Documents (Czech republic, Slovak republic) & $\begin{array}{l}\text { Period of } \\
\text { validity }\end{array}$ \\
\hline \multicolumn{3}{|c|}{ The Czech Republic } \\
\hline $\begin{array}{l}\text { Decree of the government, co-operation } \\
\text { of ministries }\end{array}$ & Strategy of Sustainable Development of the Czech Republic & until 2014 \\
\hline Decree of the government & Strategy of Economic Growth of the Czech Republic & 2005-2013 \\
\hline \multirow[t]{4}{*}{ Ministry for Regional Development } & Strategy of Regional Development of the Czech Republic & $2007-2013$ \\
\hline & National Development Plan of the Czech Republic & $2007-2013$ \\
\hline & National Strategic plan for Rural Development of the Czech Republic & $2007-2013$ \\
\hline & Spatial Development Policy of the Czech Republic & $2007-2013$ \\
\hline \multirow[t]{2}{*}{ Ministry of Agriculture } & National Strategic Plan for Rural Development of the Czech Republic & $2007-2013$ \\
\hline & Program of Rural Development of the Czech Republic & $2007-2013$ \\
\hline \multirow[t]{4}{*}{ Ministry of Environment } & National Biodiversity Strategy of the Czech Republic & since 1994 \\
\hline & State Environmental Policy & 2004-2010 \\
\hline & $\begin{array}{l}\text { Nature Conservation and Landscape Protection Programme of the } \\
\text { Czech Republic }\end{array}$ & $2004-2010$ \\
\hline & Operational Programme Environment & $2007-2013$ \\
\hline \multicolumn{3}{|c|}{ The Slovak Republic } \\
\hline \multirow[t]{2}{*}{ Decree of the government } & National Strategy of sustainable development & 2001- \\
\hline & National Competitiveness Strategy & $2005-2010$ \\
\hline \multirow{3}{*}{$\begin{array}{l}\text { Ministry of Construction and } \\
\text { Regional Development }\end{array}$} & National Plan of Regional Development & $2007-2013$ \\
\hline & National Development Plan & $2007-2013$ \\
\hline & National Strategic reference framework & $2007-2013$ \\
\hline \multirow[t]{3}{*}{ Ministry of Agriculture } & National strategic Plan for Rural Development of the Slovak Republic & 2007-2013 \\
\hline & Action Plan of Development of Ecological Agriculture & Until 2010 \\
\hline & Programme for Rural Development & $2007-2013$ \\
\hline \multirow[t]{5}{*}{ Ministry of Environment } & Conception of landscape development & 2001- \\
\hline & National Strategy of Biodiversity Protection & since 1997 \\
\hline & Strategy, principles and priorities of state environmental policy & $1993-2010$ \\
\hline & National environmental action programme & 2003-2010 \\
\hline & Operational programme of environment & $2007-2013$ \\
\hline
\end{tabular}

Note: Tactical documents are marked in bold.

Semančíková et al. (2008). Only spatial problems were defined for this study to compare hierarchical planning in the Czech and Slovak Republic. The outline and characteristics are shown in Table 2. 


\section{Definition of Problems}

In the analysis, we were interested which of the defined problems are in the studied strategic and tactical documents described and to what scope of their solution is reflected and processed in last supported activities, eventually in the consequent endowments. Evaluation of these documents was performed based on a simple key when we have defined four basic categories. Description (see Table 3). This document, which dealt with all problems and also solved them in category 1 , would be given $100 \%$ in the assessment.

\section{Results}

The research compared in all points the Czech and the Slovak Republic. Points 1 and 4 are always described. The remaining parts are only described if there is an

Table 2. Description of selected environmental issues in programming documents, own work.

\begin{tabular}{ll}
\hline $\begin{array}{l}\text { Fragmentation of } \\
\text { landscape }\end{array}$ & $\begin{array}{l}\text { Fragmentation of the landscape is a process, during which the landscape is } \\
\text { divided into smaller and smaller parts which gradually lose the ability to } \\
\text { perform its function as a space for existence of viable populations of animals. }\end{array}$ \\
Urban sprawl & $\begin{array}{l}\text { This is an uncontrolled dispersion of buildings in free landscape and hermetic } \\
\text { seal of land. }\end{array}$ \\
$\begin{array}{l}\text { Change of landscape } \\
\text { character }\end{array}$ & $\begin{array}{l}\text { The character of landscape is a significant value of preserved natural and } \\
\text { cultural heritage. It is given by specific features and signs of landscape, whose } \\
\text { change leads to culturally-aesthetic and visual pollution of landscape, meaning } \\
\text { change or degradation of landscape character. }\end{array}$ \\
$\begin{array}{l}\text { The marginalization of } \\
\text { farmland and } \\
\text { countryside }\end{array}$ & $\begin{array}{l}\text { A) Marginalization of farm land and countryside - leaving of landscape and } \\
\text { increase of percentage of unfarmed land; } \\
\text { their original use. }\end{array}$ \\
$\begin{array}{l}\text { Non-cultivated } \\
\text { landscape }\end{array}$ & $\begin{array}{l}\text { Non-cultivated landscape we understand the landscape remade by the man for } \\
\text { purpose of its use. These are for example old quarries or partially mined } \\
\text { quarries, de-sludging reservoirs, slag heaps, dumping places, polluted streams } \\
\text { without original vegetation, fallow lands, military domains etc. }\end{array}$
\end{tabular}

Table 3. Categories of assessment of documents and their description, own work.

\begin{tabular}{clc}
\hline Category & \multicolumn{1}{c}{ Description } & Point evaluation \\
\hline Category 1 & $\begin{array}{l}\text { Document describes a problem, supports its solution and describes } \\
\text { methods of this solution }\end{array}$ & 3 \\
Category 2 & $\begin{array}{l}\text { Document describes a problem, supports its solution, but does not deal } \\
\text { with the problem on }\end{array}$ & 2 \\
Category 3 & Document describes a problem, but does not deal with the problem on & 1 \\
Category 4 & Document does not mentioned the problem at all & 0 \\
\hline
\end{tabular}


interesting result, but they were always checked. After the description of all documents, the documents might be described as the whole (Figure 1)

\subsection{Fragmentation of Landscape}

The issue of fragmentation of the landscape in Slovakia is in the second place; in the Czech Republic, it is in the third place regarding the importance of spatial landscape problems (see pie charts comparing both countries). In both countries, fragmentation of the landscape is explicitly discussed by strategic documents of the ministries of Environment in category 1 and the Slovak Republic by the National Plan of Regional Development document.

From the Czech Republic's tactical documents, the issue of fragmentation of landscape is solved by Strategy of Sustainable Development of the Czech Republic, Operational Programme Environment, and in category 2. On the other hand, the Rural Development Program of the Czech Republic in category 4 does not pay any attention to it. In Slovak documents, the most attention is paid to these issues in the document Conception of landscape development. In contrast, documents Nature and landscape conservation strategy in the Slovak Republic pay their attention to it only in category 3.

The hierarchical connection of documents in the relevant issue is insufficient in both countries. Especially, tactical documents do not follow strategic documents. For example, the Spatial Development Policy of the Czech Republic does not follow the National Development Plan of the Czech Republic and Strategy of Regional Development of the Czech Republic, or in Slovakia National strategic Plan for Rural Development does not follow National Development Plan.

The solution to these problems is understood primarily in removing migration barriers in rivers and streams by building the fish-passes and minimizing the impact of roads and traffic as elements increasing fragmentation.

\subsection{Urban Sprawl}

The issue of urban sprawl is discussed similarly by $60 \%$ of the strategic documents

\begin{tabular}{|l|}
\hline \multicolumn{1}{|c|}{ Czech Republic } \\
\hline 1. General description on strategic level \\
2. Description on level of ministries \\
3. Description on level of documents - it \\
is possible to underline also what \\
solutions are proposed, if \\
interesting ... \\
4. General description on tactical level \\
5. Description on the level of ministries \\
6. Description on the level of documents \\
\end{tabular}

Slovak Republic

1. General description on strategic level

2. Description on the level of ministries

3. Description on the level of documents - it is possible to underline decisions which are also proposed, if it is interesting ...

4. General description on tactical level

5. Description on the level of ministries

6. Description on the level of the documents

Figure 1. European standards and agreements and tactical documents in Slovak and Czech Republic, own work. 
of the Czech and Slovak Republic. In both countries, they are especially documents worked out by the Ministry of Environment. State Environmental Policy, National Biodiversity Strategy of the Czech Republic, National Strategy of Biodiversity Protection and Strategy, principles, and priorities of the Slovak Republic's state environmental policy are in category 1 . In this category, the urban sprawl is discussed by Strategy of Regional Development and Strategy of Regional Development of the Czech Republic in the Czech Republic and Slovakia by the National Plan of Regional Development.

Documents, National Development Plan, National Strategic Plan for Rural Development in the Czech Republic, and National Strategy of sustainable development and National strategic Plan for Rural Development of the Slovak Republic in the Slovak Republic solve this category 3. However, the descriptive parts mention it as a troubling topic.

Tactical documents Nature Conservation and Landscape Protection Programme in the Czech Republic and Nature and landscape conservation strategy in the Slovak Republic come from the Ministry of Environment and belong to category 1 regarding document assessment. Documents such as Program of Rural Development, Operational Programme Environment, and Programme for Rural Development in the Slovak Republic solve these issues on our assessment level in category 3 , which means that they only mention it.

The hierarchical connection of tactical documents to the strategic ones is at the documents, dealing with urban sprawl, insufficient in both countries. The example can be Spatial Development Policy of the Czech Republic that is not connected to Strategy of Regional Development or Program of Rural Development to National Strategic Plan for Rural Development.

Documents, bringing a solution, can see an increase in efficiency of payments for urban sprawl with reflection to the biodiversity as an economic tool of general protection of land by the valorization of the price list for extraction of land from the Agricultural Land Fund. Or proposals of economic to prevent from the urban sprawl and propose a higher price for green fields.

\subsection{The Marginalization of Farmland and Countryside}

The marginalization of farmland and countryside as our defined spatial problem is solved by $60 \%$ of strategic documents in the Slovak Republic and $50 \%$ of strategic documents in the Czech Republic (Council of Europe Portal, 2021). Documents such as the National Strategic Plan for Rural Development and National Development Plan solve these issues only on category 3. Furthermore, in the critical strategic document-Strategy of Sustainable Development - this issue is missing entirely. A different situation is in the Slovak Republic, wherein documents such as the National Development Plan, National strategic Plan for Rural Development, and National Plan of Regional Development are solutions to these problems. Unlike the Czech Republic, the strategic document National Strategy of sustainable development of the Slovak Republic mentions the marginalization of 
fields and countryside.

The only tactical document solving the marginalization issue is the Program of Rural Development, which develops goals set in the National Strategic Plan for Rural in detail. Program of Rural Development in a solution to the mentioned problem follows the National Strategic Plan for Rural, which proves the connection of these tactical documents to the Czech Republic's strategic documents. The tactical documents such as the Operational Programme Environment, Nature Conservation, and Landscape Protection Programme of the Czech Republic or Spatial Development Policy of the Czech Republic do not solve and do not mention marginalization. Regarding tactical documents of the Slovak Republic, the situation is entirely different. The issue of Programme for Rural Development is dealt with in category 1 and other documents on levels 2 and 3.

The connection of tactical documents to the strategic ones can be seen in both countries only in the Program for Rural Development, whereas other documents miss this connection.

Documents solving this issue stress the empowering of tools for the support of sustainable development of rural areas and the use of such tools to impact the environment positively.

\subsection{Leaving of Landscape}

This problem is discussed identically in both countries by $80 \%$ of strategic documents (see both countries' pie charts). In category 1 all documents of the Ministry for Local Development of the Czech Republic and documents Spatial Development Policy of the Czech Republic and Strategy of Economic Growth of the Czech Republic support its solution and describe this solution's methods. The document of the National Strategic Plan for Rural Development of the Czech Republic does not deal with the problem and does not mention it. The National Strategy of Sustainable Development of the Slovak Republic, together with the Ministry of Local Development documents of the Slovak Republic, solves the problems in category 3.

From the tactical documents in the Czech Republic, brownfields' issue is especially Operational Programme Environment and Program of Rural Development of the Czech Republic in category 1. On the other hand, the Nature Conservation and Landscape Protection Programme of the Czech Republic ignores it. All Slovak tactical documents mention the problem and the Conception of landscape development and Programme for Rural Development support its solution.

The hierarchical connection of documents in a brownfield problem solution in the Slovak Republic is insufficient because tactical documents do not develop goals set by the strategic documents. There is a slightly better situation in the Czech Republic because, except Nature Conservation and Landscape Protection Programme of the Czech Republic, all documents deal with brownfields in higher or the same category.

A solution to the problem in both countries is seen in more intensive support 
of the revitalization of unused urbanized areas and industrial buildings, especially the program's optimization for support of industrial zones and preference of brownfields to the new construction in green fields.

\subsection{Non-Recultivated Landscape}

The solution of spatial problem-non-improved landscape is similar-in both countries, it is solved only in $30 \%$ of strategic documents. This reflects a relatively low interest in the current issue of the non-recultivated landscape. In the Czech Republic, this issue is solved only with documents from the Ministry of Environment, such as State Environmental Policy, Nature Conservation, and Landscape Protection Programme of the Czech Republic and only in categories 1 and 2. In Slovakia, strategic documents such as National Strategy of sustainable development, Strategy, principles, and priorities of state environmental policy, National Strategic reference framework and National Development Plan solve the non-recultivated landscape on the level of category 1. National Plan of Regional Development does not mention this issue at all.

Tactical documents such as State Environmental Policy or Operational Programme Environment deal with the issue; however, do not develop it. There is the only document solving it in the Czech Republic; however, only in a limited area Milovice-Mladá and other non-recultivated areas are not dealt with. In Slovakia, the document Conception of landscape development is the only one solving this issue on the level of category 2. Other tactical documents deal with the problem only on the level 3-4.

The connection of tactical documents to the strategic ones is missing in both countries.

\subsection{Change of Landscape Character}

The change of a landscape character is discussed as a spatial problem in $40 \%$ of strategic documents in the Czech Republic and 30\% of strategic documents in the Slovak Republic. This issue is dealt with in both documents only marginally. The first category of assessment of documents is solved by the Landscape Protection Programme of the Czech Republic, State Environmental Policy. On the contrary, the documents of National Strategic reference framework, Strategy of Regional Development of the Czech Republic, National Development Plan, National Strategic Plan for Rural Development do not deal with the issue of the change of landscape character as well as mention it in the descriptive parts of documents as a troubling topic. In the Slovak Republic, strategic documents National Strategy of Biodiversity Protection, Strategy, principles, and priorities of state environmental policy solve the issue on the level of category 1. Documents National Plan of Regional Development, National Strategic reference framework NSRR does not mention this issue.

Tactical documents Nature Conservation and Landscape Protection Programme of the Czech Republic, Program of Rural Development of the Czech Republic, 
and Operational Programme Environment solve this issue only on the $2^{\text {nd }} 3^{\text {rd }}$ level. In the Slovak Republic, the situation is similar to the Czech Republic, where Programme for Rural Development, Conception of landscape development, Nature and landscape conservation strategy in the Slovak Republic deal with the change of landscape character on the level 2 and 3.

The connection of tactical documents to the strategy is insufficient, such as the Nature Conservation and Landscape Protection Programme of the Czech Republic to State Environmental Policy, where the problems are only described.

Documents solving this issue put the stress on support and protection of the area's landscape character and its particular elements (lonely standing trees, stripes of greenery along the roads, wetlands and small water reservoirs, and others). Simultaneously, the stress is put on the necessity to reduce the interruption of the mountain area's landscape character by the building of vertical buildings.

In general, comparing the total shape (formulas, Figure 2 of the Czech Republic, and the Slovak Republic) of the Czech Republic and the Slovak Republic reveals long-term joint developments in one state explain significant matches of several factors different stages of programming documents. By contrast, differences can be attributed to national characteristics, such as production, socio-economic, geo-morphological, and pedo-geological specificities.

A significant match can be found with negative factors such as biodiversity degradation, brown-fields, and air quality changes. It might be due to the longterm impact of the common economic policy, where large-scale technology prevailed, and political and social relations. As discussed in both states, the degradation of biodiversity was caused by several reasons, such as abandoning in-field strips and patches, land consolidation into large soil units, cultivation of monocultures, heavy mechanization, and high doses of mineral fertilizers and preservatives. Regarding the intensity of focusing on the documents' issue, the spread of invasive species seems to be an insignificant factor, and both states consider it a potential threat. It follows a rather low degree of landscape change from declining biodiversity. The marked degree of landscape degradation can be considered undervalued and inadequate reality, so that both states should significantly focus on this issue. This is related to other problem areas, such as the disruption of ecological stability; both states have roughly the same value: the moderate degree of intensity, similar to the disruption of landscape permeability. A certain indicator of landscape stability is related to its fragmentation. There is a greater interest for this landscape problem in the Slovak Republic due to the high realization of land improvements. In the Czech Republic, the gradual approximation of the pace of fragmentation of the landscape in both countries is predicted, as reported by the new proposed documents. This finding corresponds to the permeability of the landscape, where the higher degree is indicated in the Czech Republic. The increased extent of brownfields is due both to the negative factors already mentioned and to the restructuring of the industry at the beginning of the $21^{\text {st }}$ century, the cancellation and elimination of inefficient productions, 

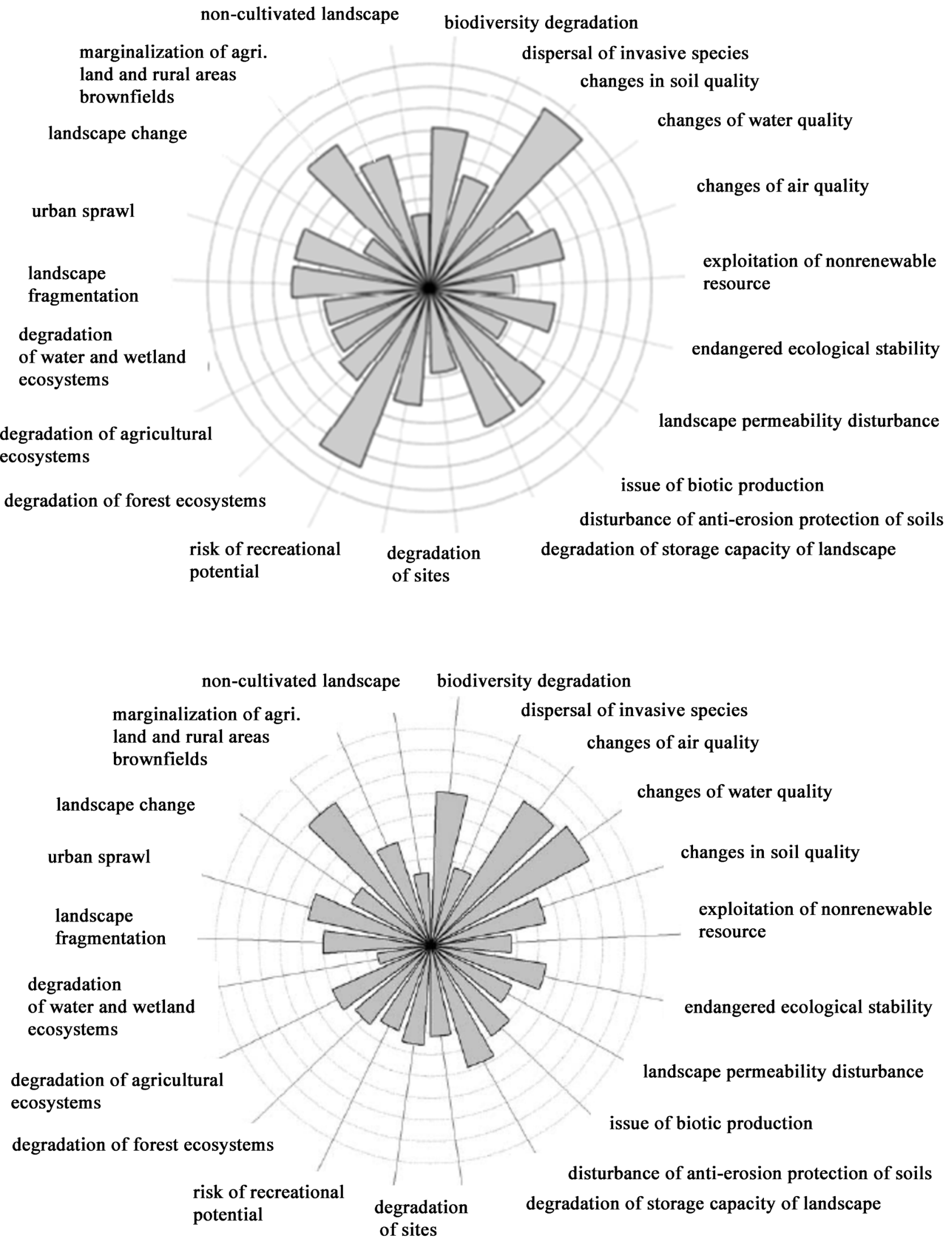

Figure 2. Landscape problems by their importance in the Slovak republic and the Czech Republic, own work. 
the transition to modern, wasteless technologies, the privatization of the land fund and the liquidation of inefficient farms, together with the uneconomic management of the land fund and the failure to observe the principles of land-use planning, and hence much attention is paid to such increase in both states. The recovery of brownfields is dealt with strategic and tactical documents in both countries. Degradation of habitats, related to the negative effects of technologies and practices, is considered a related indicator, disturbing the ecological balance in a country with a high negative impact on ecosystems. Uncultivated landscape, as a result of surface and mine extraction activities, is rather common in both states, especially in the past period. Gradual control of this activity will increase demand for reclamation in both forestry and agriculture and other areas. In this context, it is necessary to mention the reported low level of exploitation of non-renewable resources in both countries, possibly due to nuclear energy in particular. Urban sprawl is rather dynamic, so that both countries are dealing with this issue, as its high growth in recent decades is a warning sign for contemporary civilization. Water quality is more intense in the Czech Republic due to its geo-morphological character, with lowlands and mid-lands predominating the higher percentage of concentrated settlement structures and industrial agglomerations and the higher share of source areas of good groundwater in the Slovak Republic. Related degradation of water and wetland ecosystems with moderate intensity in both states impacts the quality of surface and underground water, on its accumulation, including the self-cleaning processes. As a result of the revitalization programs in both states, the intensity of degradation of the ecosystems mentioned above decreases, and programs are implemented to rebuild them and build new ones to address the supply of drinking water to the population. A landscape's retention capacity is considered a follow-up issue that is both low in the two countries. However, this issue is not addressed. This results in the occurrence of flash flood-floods and the gradual reduction of groundwater supplies for the population. The degradation of agricultural ecosystems is roughly the same in the two states. The major difference is related to the forest ecosystem, where the Slovak Republic's intensity of interest is significantly higher, and this issue is discussed a lot by the Slovak Republic. For objectivity, it is necessary to say that currently, the problem of degradation in the Czech Republic has begun to be discussed. This trend is also reflected in the next programming period. The bark beetle outbreak and wind-fallen trees, due to spruce monocultures, are negative. In the forests of the Czech Republic, there is an unfavourable species composition of the forests. Gradually, they are restored with the growing presence of deciduous species. The change in soil quality is average in both states. It can be said that this does not correspond to the current reality. The soil erosion risk in the Czech Republic is reported for more than $60 \%$ of soils; in Slovakia, this percentage is lower (40\%), yet this factor can be mentioned as limiting future management of the soil fund. The loss of the most fertile soil particles into the watercourses gradually reduces the production capacity of soils. It is an irreplaceable 
loss of national wealth, significantly reducing water quality and increasing the cost of its treatment for drinking purposes. For these reasons, the issues mentioned above should be reflected in all documents much more intensely and should be more pronounced in the following period. At the middle level, there is a problem of biotic production, which is threatened in both states, with a growing negative trend, and both countries should focus more on this issue in the future.

In conclusion, both samples' results reflect both the shared history and the profiling of national differences and specifics. It is necessary to mention the need for a common European area, where globalization and internationalization elements are increasingly intensified in developing these independent state units today, both as a positive and negative tendency. As examples, there are the European agreements, treaties, and programs, where national interests and specifics are not always fully respected and intensified.

\section{Discussion}

The most critical procedural links of planning are the creation of strategic documents and, on the other hand, the development of action plans. In distinguishing three primary strategic management stages: strategic-tactical-operational (implementation) stage, programming is part of the tactical phase. This distinction is mostly not observed in Czech practice. A proper distinguishing of these stages is essential in methodology, implementation, and monitoring (control and feedback). It is not that important if different stages are presented by single documents (strategy-program-optimal implementation plan and the development should be directed this way), or some stages are integrated into one document, as is the case with the current EU methodology for the creation of operational programs, including (conciliatory) tactical and implementation stages. In the Czech Republic and the Slovak Republic, creating strategic management documents has evolved in two different directions. The programming stage at national and regional levels usually lacks the strategic stage, and the programming stage is merged with the implementation. One of the most vital impulses (perhaps at least the strongest impulse) was the concept of operational programs linked to the EU Structural Funds. The change might be related to the current move from the EU level to a "more strategic concept," as declared in the 2007-2013 documents. The continuity of the programs with the European Strategy and the National Strategy, the National Strategic Reference Frameworks, is very strongly required and should be one of the necessary conditions for their acceptance by the EU.

Given that "the Czech and Slovak conception has always copied the European conception during the last eight years, the Czech Republic and the Slovak Republic are expected to move towards a more strategic concept of governance, mostly regional, in the coming years. However, such a newly created hierarchical planning structure has some weaknesses in terms of landscape issues. Semančíková et al. (2008) dealt with the links between existing strategic, long-term, tactical, and medium-term documents at national levels drawn up by the Ministries 
for Local Development, Agriculture, and the Environment. Their research revealed that although a hierarchical structure of planning was created, individual ministries' approaches to the landscape and its planning are uncoordinated. They are not unified, and they do not have sufficient tools to involve the public and local and regional authorities. The National tactical document setting the framework for spatial planning is the 2006 Spatial Development Policy. The document should implement the goals of national strategies and transfer them to the Czech Republic regions. It should contribute to the protection, management, and improvement of the lands by adopting specific spatial measures, particularly considering better organizing interactions between different sectoral policies and their territorial impact. However, the Spatial Development Policy in its current wording neglects the development of the landscape entirely. It cannot be sufficiently integrated into the spatial planning process and into sectoral policies such as economics, agriculture, infrastructure and urban development, culture, the environment, and social development, all of which directly or indirectly influence the development of the landscapes. As a result of this deficiency, there are many mistakes in planning, managing, and using the landscape. As reported by the results mentioned above, the spatial issues are, at least, mentioned in all strategic and tactical documents on average. Also, the order of importance of problems is similar in Czech and Slovak documents (see the figure comparing the Slovak Republic and the Czech Republic). In the strategic documents, the most attention is paid to brownfields problems and the least attention to the uncultivated landscape in the Czech Republic and landscape change in the Slovak Republic. For tactical documents, the order of importance of issues in both countries is again almost identical. Only in the Czech Republic, the most attention is paid to brownfields, which are in fourth place in Slovakia.

\section{Conclusion}

Comparing both countries' strategic documents revealed that many strategic documents were created only for formal reasons until 2007, not to achieve a certain change in the landscape. In the conception documents, the analytic part is highlighted too much compared to the strategy and proposals, which are poor, with a small number of new proposals (measures), often burdened by the document's wide range. The documents' weakness is the lack of a strong link to other documents and a lack of their interdependence. For strategic documents, ex-ante evaluation is used in practice. It is an assessment of a national document before it is approved. Evaluators submit their suggestions and comments, subsequently incorporated into the document. However, the document is sometimes not adapted to the Evaluation Committee's recommendations for the reasons of time and is approved despite the comments. The purpose of strategic (program) documents is to reach an agreement with all relevant actors on the region's development strategy and sphere. The way it was created is more important than the resulting formal form of a program document. To achieve the desired development at the 
national level, it is necessary to formulate strategy/strategies for achieving this state. It is a set of follow-up activities leading to the objectives.

The fundamental characteristic of strategic planning is that it involves uncertainty planning, which requires a systematic approach to identifying and analysing external factors and their impact on the process under review. At present, strategic planning is a systematic process that involves selecting objectives, tasks, and activities needed to achieve them. In the study, the authors want to discuss the vertical links between the strategic and tactical documents and the horizontal links between the ministries where the documents come from. The study dealt with twelve documents; ten strategic and tactical documents were discussed within the Slovak Republic. The analyses revealed that although these documents both directly and indirectly deal with the landscape issue, there is a lack of a comprehensive strategy of working with the landscape.

Regarding the horizontal links between the documents, which show the cooperation of different ministries and their departments dealing with the issue, there was an uncoordinated approach and poor systemic management of the ministries in dealing with landscape issues. The only joint project is the Sustainable Development Strategy. The origins of the individual documents and their duration in both countries are presented from the tables and diagrams. The documents are thematically the same, but the contents are often different. The ministerial documents listed were adopted to implement international agreements. Most documents refer to sustainable development principles but do not pay equal attention to its three fundamental pillars: economic, social, and environmental.

A significant output of our study is how the individual documents deal with landscape and methodology, based on which it is possible to compare given documents and their quality.

\section{Conflicts of Interest}

The authors declare no conflicts of interest regarding the publication of this paper.

\section{References}

Allmendinger, P., \& Haughton, G. (2010). Spatial Planning, Devolution and New Planning Spaces. Environment and Planning C: Government and Policy, 28, 803-818. https://doi.org/10.1068/c09163

Allmendinger, P., \& Haughton, G. (2013). The Evolution and Trajectories of English Neoliberal Spatial Governance: "Neoliberal" Episodes in Planning. Planning Practice and Research, 28, 6-26. https://doi.org/10.1080/02697459.2012.699223

Antrop, M., \& Van Eetvelde, V. (2000). Holistic Aspects of Suburban Landscapes: Visual Image Interpretation and Landscape Metrics. Landscape and Urban Planning, 50, 43-58. https://doi.org/10.1016/S0169-2046(00)00079-7

Bičík, I., Janoušek, Z., \& Kabrda, J. (2015). Czechia: Changes in Landscape Use in the Transformation Period. Romanian Journal of Geography, 59, 3-17.

Boháčková, I., \& Hrabánková, M. (2006). Process Analysis-The Proposal of Method for 
Evaluation of the Effectiveness of the Use of Structural Supports at the Regional Level. Agricultural Economics-Czech, 52, 578-587. https://doi.org/10.17221/5068-AGRICECON

Boucnikova, E., Fanta, J., \& Líšková, Z. (2005). The Function of Landscape Planning in the System's Operating of Development and Landscape Use. Proceedings of CZ-IALE Conference: Landscape Ecology and Landscape Planning. Proceedings of Landscape Ecology, Vol. 2, 5-11.

Bunnell, F. L., \& Boyland, M. (2003) Decision-Support Systems: It's the Question Not the Model. Journal for Nature Conservation, 10, 269-279. https://doi.org/10.1078/1617-1381-00027

Council of Europe Portal (2021). Explanatory Report to the European Landscape Convention. https://www.coe.int/en/web/conventions/full-list/-/conventions/treaty/176

Fraser, E. D. G., Dougill, A. J., Mabee, W. E., Reed, M., \& McAlpine, P. (2006). Bottom Up and Top Down: Analysis of Participatory Processes for Sustainability Indicator Identification as a Pathway to Community Empowerment and Sustainable Environmental Management. Journal of Environmental Management, 78, 114-127. https://doi.org/10.1016/j.jenvman.2005.04.009

Hersperger, A. M., \& Bürgi, M. (2009). Going beyond Landscape Change Description: Quantifying the Importance of Driving Forces of Landscape Change in a Central Europe Case Study. Land Use Policy, 26, 640-648. https://doi.org/10.1016/j.landusepol.2008.08.015

Jehlička, P., \& Smith, J. (2011). An Unsustainable State: Contrasting Food Practices and State Policies in the Czech Republic. Geoforum, 42, 362-372. https://doi.org/10.1016/j.geoforum.2011.01.005

Kadlecová, V., Dramstad, W. E., Semancikova, E., \& Edwards, K. R. (2012). Landscape Changes and Their Influence on the Heterogeneity of Landscape of the South Bohemian Region, the Czech Republic. International Journal of Sustainable Development and World Ecology, 19, 546-556. https://doi.org/10.1080/13504509.2012.740512

Kessler, J. J. (2000). Strategic Environmental Analysis: A Framework to Support Analysis and Planning of Sustainable Development. Impact Assessment and Project Appraisal, 18, 295-307. https://doi.org/10.3152/147154600781767303

Kessler, J. J. (2003). Working towards SEAN-ERA. A Framework and Principles for Integrating Environmental Sustainability into Planning. Wageningen University and Research Centre.

Lipský, Z. (1995). The Changing Face of the Czech Rural Landscape. Landscape and Urban Planning 31, 39-45. https://doi.org/10.1016/0169-2046(94)01034-6

Millennium Ecosystem Assessment (2005). Ecosystems and Human Well-Being: Synthesis. Island Press.

Naveh, Z. (2001). Ten Major Premises for a Holistic Conception of Multifunctional Landscapes. Landscape and Urban Planning, 57, 269-284. https://doi.org/10.1016/S0169-2046(01)00209-2

Ndubisi, F. (2002). Ecological Planning: A Historical and Comparative Synthesis. The Johns Hopkins University Press.

Ndubisi, F. (2014). A Synthesis of Approaches to Ecological Planning. In F. O. Ndubisi (Ed.), The Ecological Design and Planning Reader (pp. 404-426). Island Press. https://doi.org/10.5822/978-1-61091-491-8 35

Oliveira, E., \& Hersperger, A. M. (2018). Governance Arrangements, Funding Mechanisms 
and Power Configurations in Current Practices of Strategic Spatial Plan Implementation. Land Use Policy, 76, 623-633.

https://doi.org/10.1016/j.landusepol.2018.02.042

Palang, H., Mander, Ü., \& Naveh, Z. (2000). Holistic Landscape Ecology in Action. Landscape and Urban Planning, 50, 1-6. https://doi.org/10.1016/S0169-2046(00)00076-1

Palang, H., Printsmann, A., Gyuró, É., Urbanc, M., Skowronek, E., \& Woloszyn, V. (2005). The Forgotten Rural Landscapes of Central and Eastern Europe. Landscape Ecology, 21, 347-357. https://doi.org/10.1007/s10980-004-5034-x

Pinto-Correia, T., Primdahl, J., \& Pedroli, B. (2018). European Landscapes in Transition: Implications for Policy and Practice. Cambridge University Press. https://doi.org/10.1017/9781107707566

Pražan, J., Ratinger, T., \& Krumalova, V. (2005). The Evolution of Nature Conservation Policy in the Czech Republic-Challenges of Europeanization in the White Carpathians Protected Landscape Area. Land Use Policy, 22, 235-243. https://doi.org/10.1016/j.landusepol.2003.09.010

Primdahl, J. (2014). Agricultural Landscape Sustainability under Pressure: Policy Developments and Landscape Change. Landscape Research, 39, 123-140. https://doi.org/10.1080/01426397.2014.891726

Růžička, M., \& Miklós, L. (1990). Basic Premises and Methods in Landscape Ecological Planning and Optimization. In I. S. Zonneveld, \& R. T. T. Forman (Eds.), Changing Landscapes: An Ecological Perspective (pp. 233-260). Springer-Verlag. https://doi.org/10.1007/978-1-4612-3304-6 13

Semančíková, E., Dvořáková-Líšková, Z., \& Holcová, V. (2008). How Strategic Planning Deals with Spatial Landscape Problems? In J. Kabrda, \& I. Bičík (Eds.), Man in the Landscape across Frontiers: Landscape and Land Use Change in Central European Border Regions. Conference Proceedings of the IGU/LUCC Central Europe Conference 2007 (pp. 153163). LUCC, Charles University, Faculty of Science.

Stürck, J., \& Verburg, P. H. (2017). Multifunctionality at What Scale? A Landscape Multifunctionality Assessment for the European Union under Conditions of Land Use Change. Landscape Ecology, 32, 481-500. https://doi.org/10.1007/s10980-016-0459-6

Syrbe, R.-U., \& Walz, U. (2012). Spatial Indicators for the Assessment of Ecosystem Services: Providing, Benefiting and Connecting Areas and Landscape Metrics. Ecological Indicators, 21, 80-88. https://doi.org/10.1016/j.ecolind.2012.02.013

Walz, U. (2011). Landscape Structure. Landscape Metrics and Biodiversity. Living Reviews in Landscape Research, 5, 1-35. http://www.livingreviews.org/lrlr-2011-3 https://doi.org/10.12942//rlr-2011-3 